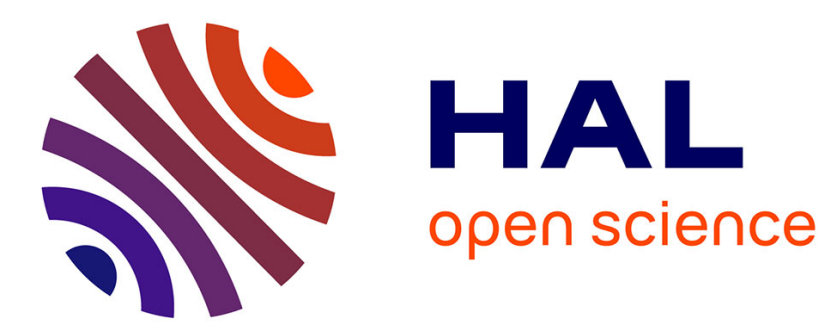

\title{
Observed decadal tropical Pacific-North Atlantic teleconnections
}

\author{
W. A. Muller, Claude Frankignoul, Nadine Chouaib
}

\section{To cite this version:}

W. A. Muller, Claude Frankignoul, Nadine Chouaib. Observed decadal tropical Pacific-North Atlantic teleconnections. Geophysical Research Letters, 2008, 35 (24), pp.L24810. 10.1029/2008GL035901 . hal-00365183

\section{HAL Id: hal-00365183 \\ https://hal.science/hal-00365183}

Submitted on 23 Jul 2021

HAL is a multi-disciplinary open access archive for the deposit and dissemination of scientific research documents, whether they are published or not. The documents may come from teaching and research institutions in France or abroad, or from public or private research centers.
L'archive ouverte pluridisciplinaire HAL, est destinée au dépôt et à la diffusion de documents scientifiques de niveau recherche, publiés ou non, émanant des établissements d'enseignement et de recherche français ou étrangers, des laboratoires publics ou privés. 


\title{
Observed decadal tropical Pacific-North Atlantic teleconnections
}

\author{
W. A. Müller, ${ }^{1}$ C. Frankignoul, ${ }^{2}$ and N. Chouaib ${ }^{2}$ \\ Received 9 September 2008; revised 13 November 2008; accepted 20 November 2008; published 30 December 2008.
}

[1] Observations of the last century are considered to investigate the decadal scale Pacific/North Atlantic teleconnections. By using wavelet analysis we find a significant low-frequency coherency between major indices of climate variability. In particular, at periods between 10 and $20 \mathrm{yr}$, the North Atlantic Oscillation (NAO) tends to be out of phase with the El Niño/Southern Oscillation (ENSO) (strong Icelandic low during La Niña) and the Pacific Decadal Oscillation (PDO), but in phase with the North Pacific Index (NPI). Hence, the Icelandic low is strong during La Niña, but the Aleutian low is weak. The band-pass SST pattern shows a close relationship between the "decadal-ENSO" mode in the Pacific and the sea surface temperature anomaly tripole in the Atlantic, consistent with the low-frequency global teleconnections. The spatial sea level patterns corresponding to the bandpass filtered indices suggest that the Aleutian-Icelandic Low seesaw is a main interbasin link on decadal time scale, consistent with the larger coherency of the NPI with the NAO than with ENSO. Citation: Müller, W. A., C. Frankignoul, and N. Chouaib (2008), Observed decadal tropical Pacific-North Atlantic teleconnections, Geophys. Res. Lett., 35, L24810, doi:10.1029/2008GL035901.

\section{Introduction}

[2] Patterns of decadal scale climate variability encompass various regional phenomena over the Pacific, Atlantic and Indian Ocean. However, their relations are complex and only partly understood. For example, the observed pattern of decadal SST variability in the Pacific is somewhat different from the interannual El Niño Southern Oscillation (ENSO) signal and also linked to Indian Ocean changes [Deser et al., 2004], atmospheric variability in the North Pacific as described by the North Pacific Index (NPI), and oceanic advection changes [e.g., Schneider and Cornuelle, 2005]. However, a significant fraction of the low-frequency variability of the NPI, which measures the sea level pressure changes over the central North Pacific and is largely associated with the PNA teleconnection pattern [Trenberth and Hurrell, 1994], comes from the ENSO teleconnections [Hurrell, 1996], so that the NPI and ENSO are highly correlated. The ENSO phenomenon also has a weak but significant impact during winter on the North Atlantic Oscillation (NAO), the main mode of variability in the North Atlantic-European (NAE) sector, since a signal resembling a positive phase of the NAO is found during strong La Niña events, and conversely a negative NAO

\footnotetext{
${ }^{1}$ Max Planck Institute for Meteorology, Hamburg, Germany.

${ }^{2}$ LOCEAN, IPSL, Université Pierre et Marie Curie, Paris, France.
}

Copyright 2008 by the American Geophysical Union. 0094-8276/08/2008GL035901 phase may be associated with El Niño events [e.g., Fraedrich and Müller, 1992]. The ENSO influence on the NAE region, however, is difficult to detect because of its seasonal modulation and non-linearity [Brönnimann, 2007], and it may be affected by decadal processes such as the Pacific Decadal Oscillation (PDO) [Brönnimann et al., 2007]. In addition, sea surface temperatures (SST) anomalies in the North Atlantic have some influence on the NAO [e.g., Frankignoul and Kestenare, 2005], so that there is no consensus on which parts of the ocean contribute to the observed low-frequency evolution of the NAO [e.g., Sutton and Hodson, 2003]. Kucharski et al. [2006] has shown that there a strong relation between multidecadal variations of the NAO and SST in the western tropical Pacific. Hence, the dominant patterns of decadal variability may well be global, and indeed observed gridded surface temperatures and precipitation [Allan, 2000; Deser et al., 2004], heat content anomalies [Meehl et al., 1998], and proxy-based records [Cobb et al., 2001] suggest close interbasin correspondences.

[3] Yet, little is known on the relation between the NAO and ENSO at the decadal scale. Here, we use wavelet analysis to investigate the link between ENSO and the $\mathrm{NAO}$ in the time-frequency domain, and further consider their link with the NPI and the PDO. Strong relations between all these indices are found at periods between 10 and 20 years, confirming the interbasin links and stressing the role of extratropical atmospheric teleconnections.

\section{Data and Methods}

[4] Our analysis is based on seasonal means of various observational dataset and normalized indices for the period 1900-2006. The NAO index is derived from Hurrell [1996] and based on the first principal component (PC) of the SLP anomalies (SLPA) for the NAE region in each season (winter is December, January and February, etc). A continuous time series was constructed from the 4 seasonal times series. For ENSO, we use NINO3 and NINO4 indices (the SST anomaly (SSTA) in $5^{\circ} \mathrm{N}-5^{\circ} \mathrm{S}, 90^{\circ} \mathrm{W}-150^{\circ} \mathrm{W}$ and $5^{\circ} \mathrm{N}-5^{\circ} \mathrm{S}, 160^{\circ} \mathrm{E}-150^{\circ} \mathrm{W}$, respectively) given in http:// ingrid.ldeo.columbia.edu/SOURCES/.Indices/.nino/. The NPI is the area weighted SLPA in $30^{\circ}-60^{\circ} \mathrm{N}, 160^{\circ} \mathrm{E}-$ $140^{\circ} \mathrm{W}$ as defined by Trenberth and Hurrell [1994] and the PDO index is the leading PC of monthly SSTA in the North Pacific [Mantua et al., 1997]. We also consider gridded fields of SSTA and SLPA taken from the MetOffice HadISST v1.1 dataset [Rayner et al., 2003] and Trenberth and Paolino [1980], respectively. Finally, we use an Aleutian-Icelandic low seesaw index (AII) as the difference of SLPA in the Aleutian Low (AL, $180^{\circ} \mathrm{W}-120^{\circ} \mathrm{W}, 35^{\circ} \mathrm{N}-$ $55^{\circ} \mathrm{N}$ ) and the Icelandic Low (IL, $60^{\circ} \mathrm{W}-0^{\circ}, 55^{\circ} \mathrm{N}-70^{\circ} \mathrm{N}$ ) regions [Honda et al., 2001]. The seasonally averaged indices and fields were linearly detrended prior to the analysis. 

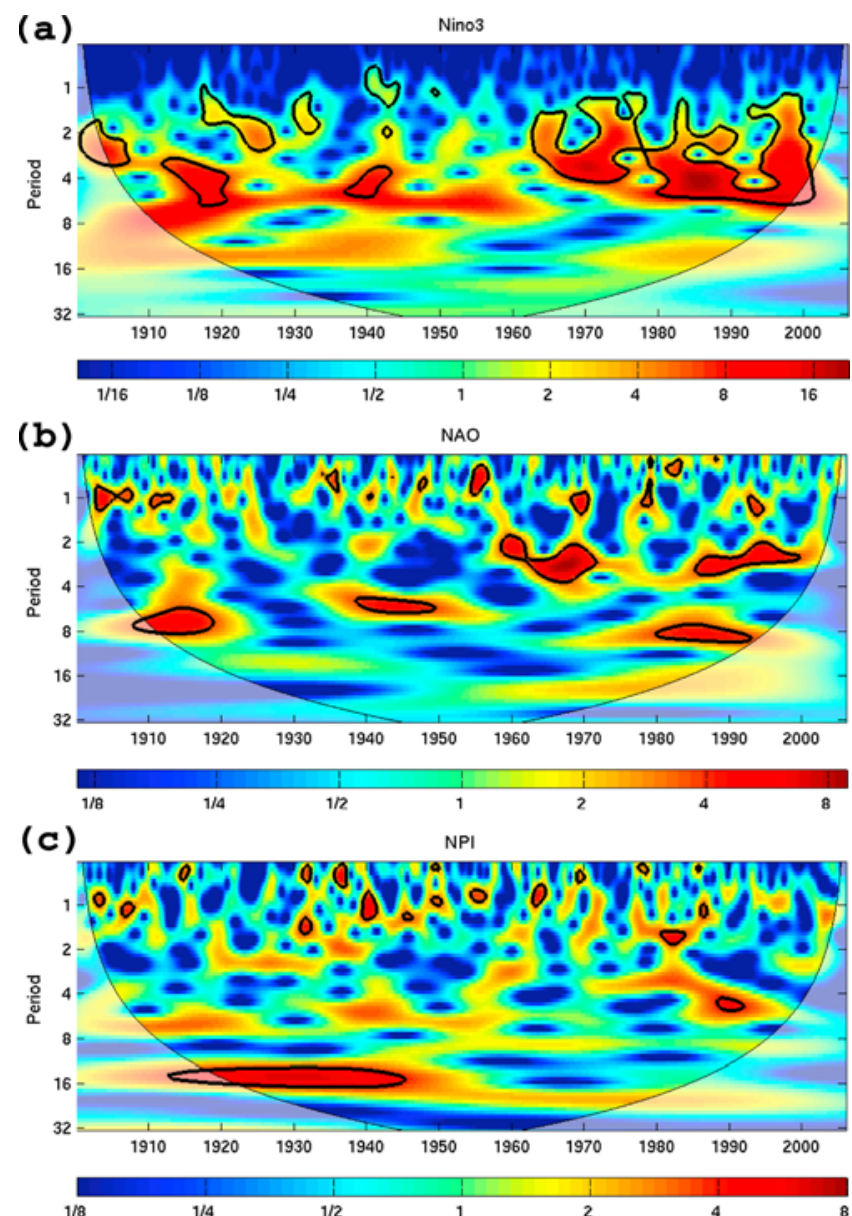

(d)

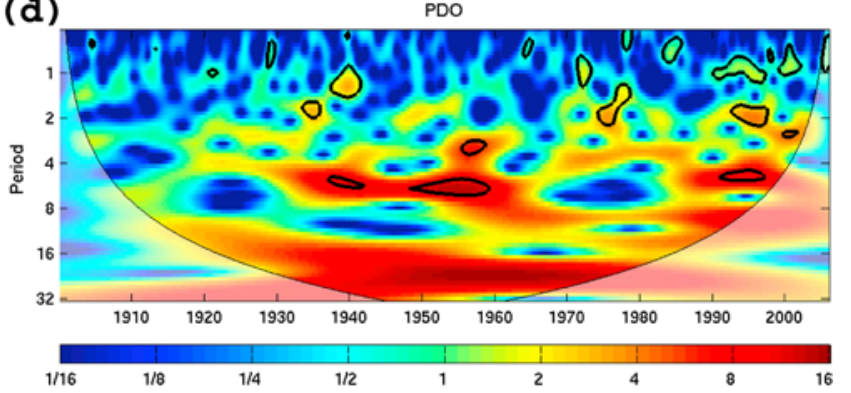

(e)

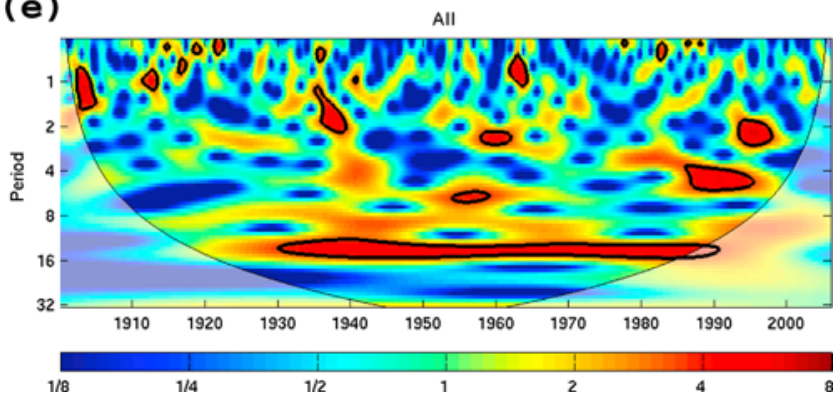

Figure 1. Wavelet power spectrum, normalized by the variance of (a) NINO3, (b) NAO, (c) NPI, (d) PDO and (e) AII for all seasons. The ordinate is the Fourier period in $\mathrm{yr}$, the abscissa is time. The thick contour encloses regions of greater than $95 \%$ confidence and the thin line indicates the limit of the cone of influence.
[5] Wavelet analysis is made with the Morlet wavelet, and the transform is performed in Fourier space [Torrence and Compo, 1998], using zero padding to reduce wraparound effects. Parameters are chosen to give a total of 57 scales ranging from 0.5 to 64 yr. To test for nonstationary changes in power and spectral peaks, the wavelet spectrum is compared to an AR1 process. The wavelet power spectrum is distributed as a chi-square variable about the AR-1 spectrum, with 2 degrees of freedom. The wavelet square coherency and phase are calculated using smoothing in the time and space domain [Grinsted et al., 2004], with the $5 \%$ significance level determined from a Monte-Carlo simulation of 1,000 sets of surrogate time series. Grinsted et al. [2004] use surrogate red noise (AR-1), which is reasonable for the NAO, the NPI or the PDO, but not for ENSO. Here we use a surrogate AR-2 time series for ENSO. The wavelet analysis shows that NINO3 and NINO4 are similar, except that there is more low-frequency energy in NINO4 since about 1960 . For brevity we present results for NINO3.

[6] To focus on periods $\mathrm{T}$ between 10 and $20 \mathrm{yr}$ and filter out both the interannual ENSO signal and the multi-decadal climate variability, we band-pass filter, using an inverse wavelet transformation. The significance of regressions and correlations based on the band-pass filtered data is estimated from subsampled data at $5 \mathrm{yr}$ interval, taking into account their lag one autocorrelation [Bretherton et al., 1999].

\section{Decadal Teleconnections}

[7] The wavelet power spectrum of NINO3 (Figure 1a) shows broad energy peaks between $\mathrm{T}=2$ and $6 \mathrm{yr}$, with well-known features such that the higher amplitude of the ENSO events and the shift of the dominant energy peak toward larger period between 1970 and 2000. There are also small energy peaks at decadal periods, which are found in each season separately (not shown). The NAO spectrum is basically white, although there is a significant peak at $\mathrm{T}=2$ to 3 yr during much of the 1960-2000 period, and a few isolated peaks between $\mathrm{T}=5$ and $10 \mathrm{yr}$ (Figure 1b). When performing the analysis with one season only, the peaks are seen in at least one or two seasons, but usually not in summer when the NAO signal is weak.

[8] The coherency between NINO3 and the NAO is generally small in the 2 to $4 \mathrm{yr}$ domain, consistent with the lack of significant correlation between the two indices (Figure 2a). However, when coherent, the two indices are out-of-phase. Throughout this paper, an out-of-phase (inphase) relation between two indices indicates that a positive index 1 is associated with a negative (positive) index 2, and vice versa. Hence the NAO is in a positive phase during $\mathrm{La}$ Nina. Interestingly, the NAO and NINO3 are often significantly coherent between $\mathrm{T}=5$ and $10 \mathrm{yr}$, and the two indices are coherent throughout the whole period near $\mathrm{T}=10$ to $20 \mathrm{yr}$. All significant coherencies indicate an out-of-phase relation between NAO and NINO, except for $\mathrm{T} \approx 6$ to $8 \mathrm{yr}$ before 1925 , when the two variables vary in phase (also found when using station data for the NAO). In general, the coherencies tend to be largest in winter and spring, and smallest in fall (not shown).The location of significant coherency in the frequency-time domain varies somewhat with the season, presumably reflecting the limited smoothing in the coherency calculation. The strong coherency between NINO and 
(a)

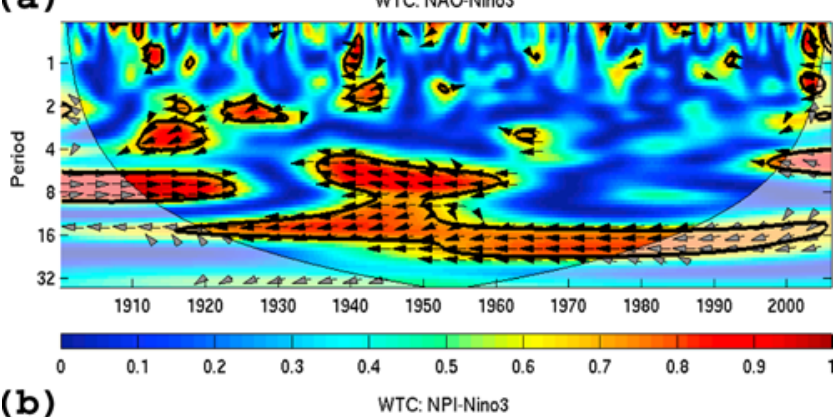

(b)

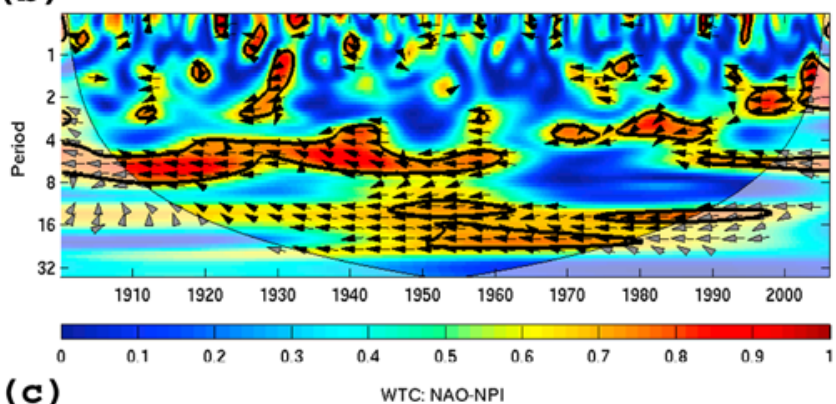

(c)
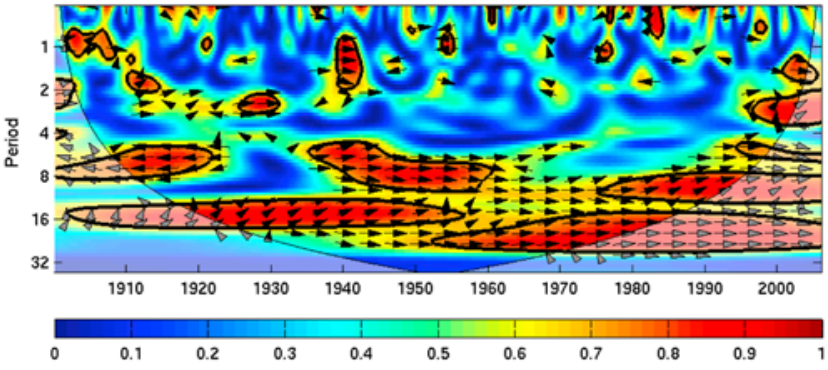

(d)

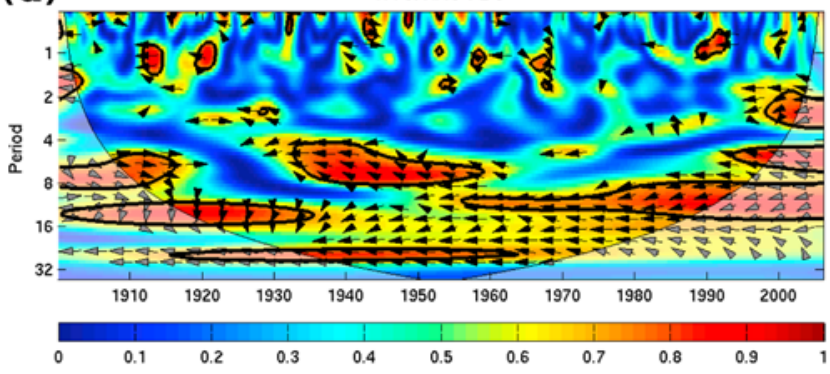

(e)

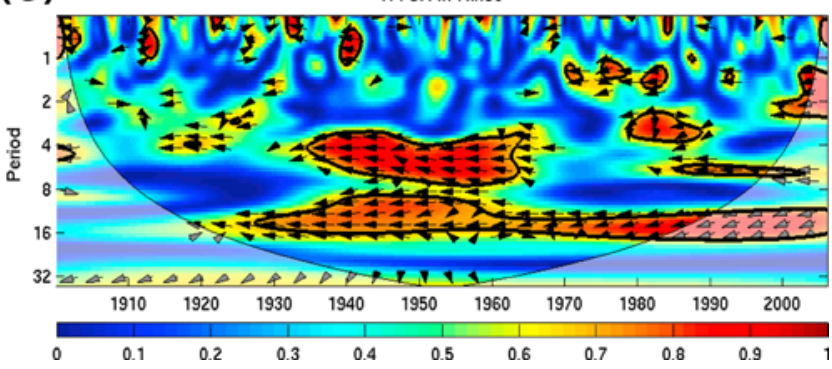

Figure 2. Wavelet coherency of (a) NAO and NINO3, (b) NPI and NINO3, (c) NAO and NPI, (d) NAO and PDO and (e) AII and NINO3 for all seasons. The vectors indicate the phase difference (in phase is toward the right, and e.g., variable 1 preceding variable 2 toward the bottom). The thick contour encloses regions of greater than 95\% confidence and the thin line indicates the limit of the cone of influence.
NAO at periods between 10 and $20 \mathrm{yr}$ is robust and depends very little on the way statistical significance is estimated, and to our knowledge it has not been documented before (previously based on low-pass filter [e.g., Kucharski et al., 2006]). Comparison of the $10-20$ yr band-pass filtered indices underlines this strong connection (Figure 3a), with a significant correlation $\mathrm{r}=-0.66$. The band-pass filtered ENSO index strongly resembles indices based on other techniques and proxy-based climate records [e.g., Cobb et al., 2001].

[9] To try understanding the origin of the decadal link between ENSO and the NAO, we explore whether the indices are related to the North Pacific variability, represented by the NPI and the PDO. The wavelet power spectrum of the NPI (Figure 1c) is largely white, but with pronounced peaks near 15-yr period, while the PDO spectrum (Figure 1d) is red, consistent with the forcing of the North Pacific SST by the atmosphere [Schneider and Cornuelle, 2005]. The two Pacific indices are highly coherent and out-of-phase (not shown), and closely linked to NINO3, as illustrated for NPI in Figure 2b [see also Hurrell, 1996]. Note that the coherency is particularly strong at T between 4 and $8 \mathrm{yr}$, and somewhat weaker between 10 and $20 \mathrm{yr}$. The same holds for the coherency between NINO3 and PDO (not shown), except that the low-frequency coherency is a little stronger. The correlation between the 10-20 yr band-pass filtered
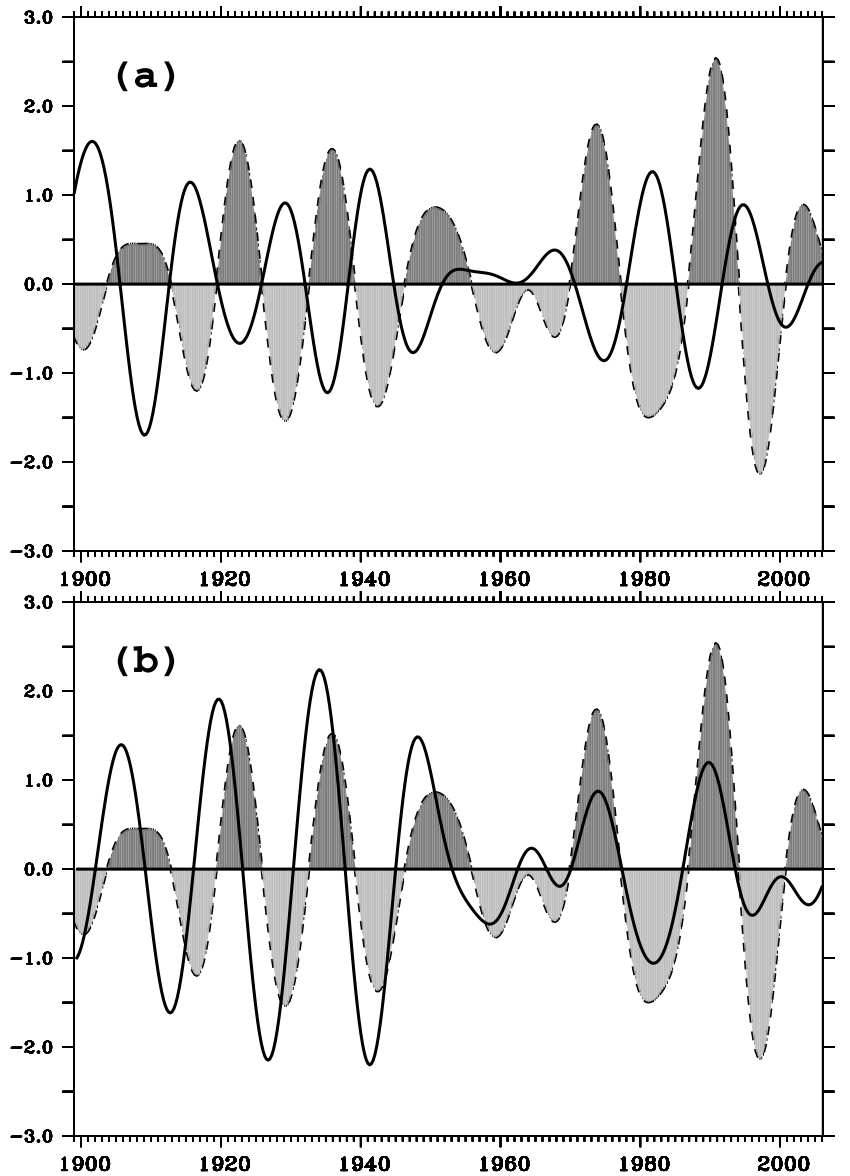

Figure 3. Wavelet $10-20 \mathrm{yr}$ band-pass filtered time series of (a) NAO and Nino3 and (b) NAO and NPI for all seasons. Shaded is the NAO index. 
(a)

(b)

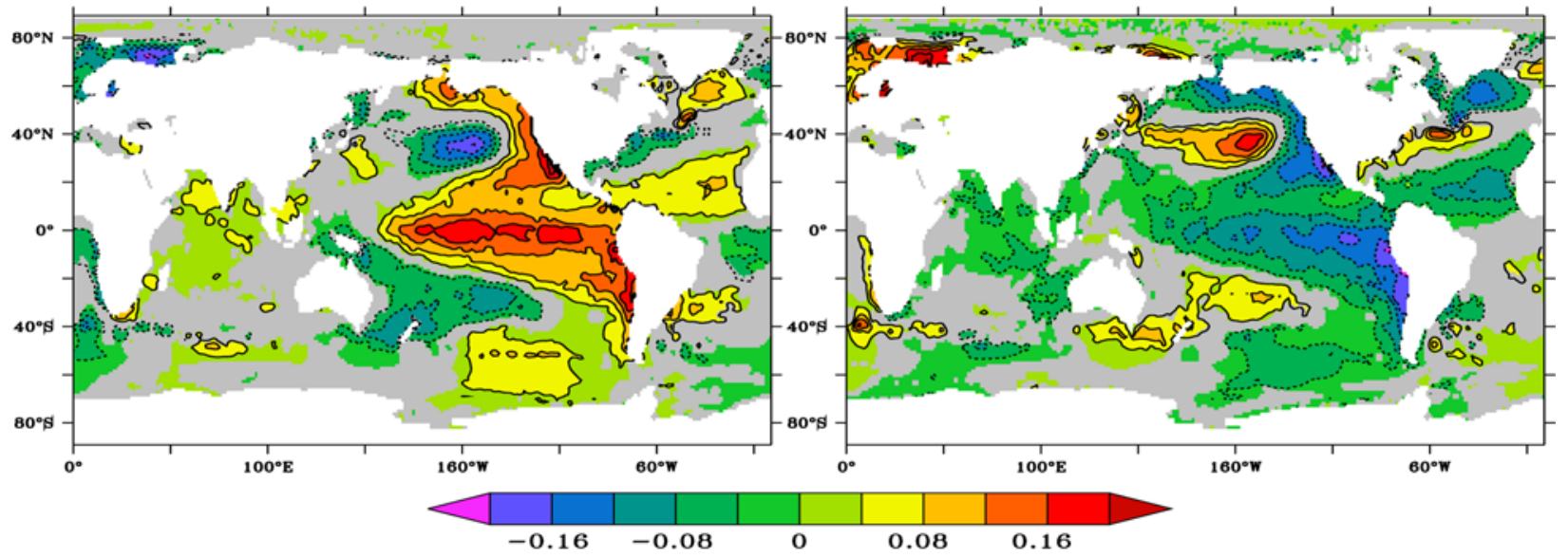

(c)

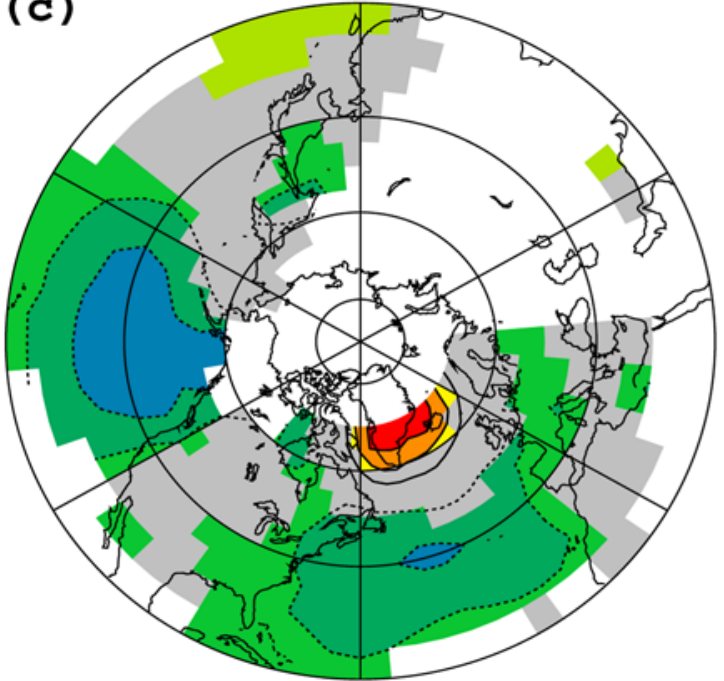

(d)
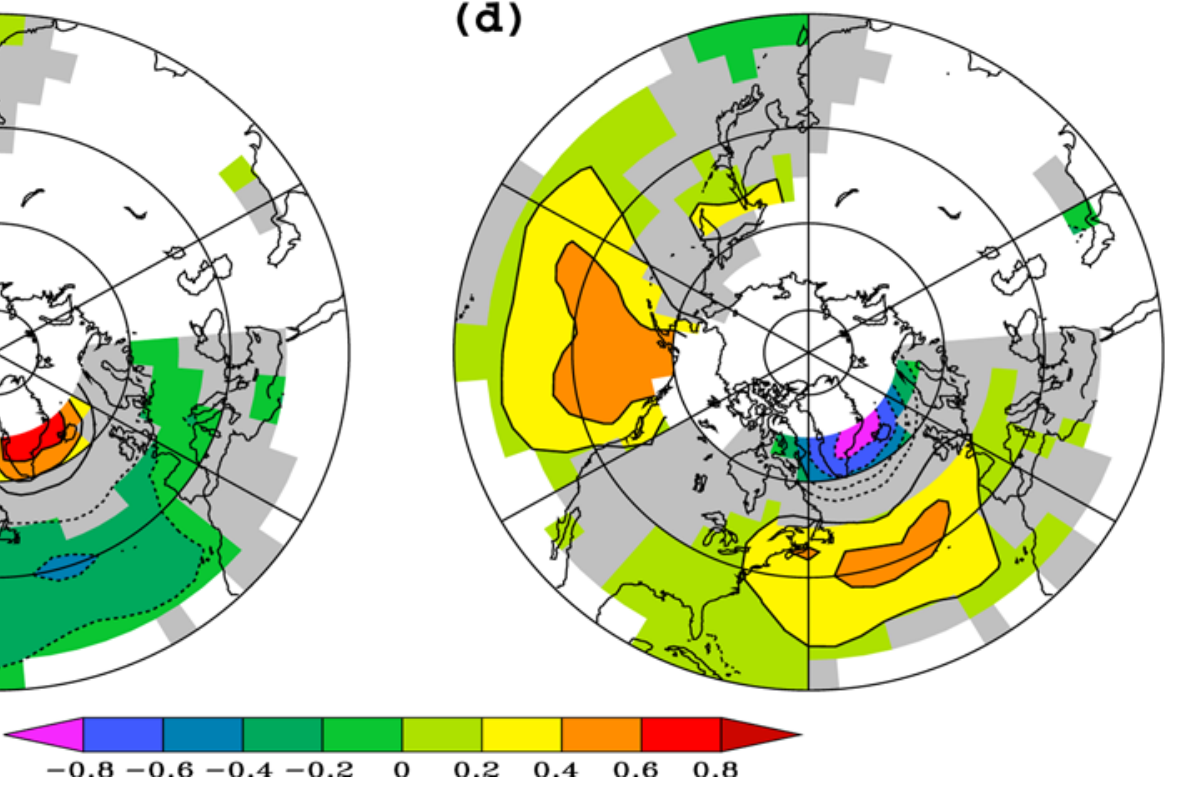

Figure 4. Regression of winter ( $a$ and b) SSTA and (c and d) SLPA onto the band-passed Nino3 (a and c) and NAO index (b and d). Contour intervals are $0.04^{\circ} \mathrm{C}(\mathrm{a}$ and b) and $0.2 \mathrm{hPa}$ (c and d). Colors indicate significant values at the $90 \%$ level. Grey and colored regions show data coverage.

NPI (PDO) and NINO3 index is $r=-0.50(0.49)$. It is weaker during the first half of the century than during the second one, possibly because of the poorer data coverage.

[10] As shown in Figure 2c, the NAO and the NPI are highly coherent and out-of-phase at periods longer than $4 \mathrm{yr}$. The two indices vary in phase (except that the phase is reversed near $\mathrm{T} \approx 6$ to $8 \mathrm{yr}$ before 1925 , as it was between the NAO and NINO3). There is no clear indication of a lead/lag relation, except at low frequency in the first half of the century, where the NPI slightly precedes the NAO, as clearly seen in the band-pass filtered time series in Figure $3 \mathrm{~b}$. A substantial (albeit slightly lower) low-frequency coherency is also found between the NAO and the PDO (Figure 2d), which are out-of-phase, except again near $\mathrm{T} \approx 6$ to $8 \mathrm{yr}$ before 1925. A comparison between Figures 1 and 2 shows that the time-frequency domains where the NAO and the NPI (PDO) are highly coherent at periods longer than $4 \mathrm{yr}$ are also those where the NAO and NINO3 are coherent. Moreover, the coherency between the NAO and the NPI
(PDO) tends to be larger than between NINO3 and NPI (PDO). The NAO and the NPI indices have in fact similar low-frequency peaks, although they are more significant for the NAO at $\mathrm{T}=4$ to $10 \mathrm{yr}$, and for the NPI at lower frequency (Figures $1 \mathrm{~b}$ and $1 \mathrm{c}$ ). This suggests that the NPI is more strongly linked at low frequencies to the NAO than to ENSO.

[11] To document the spatial patterns associated with this decadal variability, SSTA and SLPA are regressed onto the 10-20 yr band-passed filtered indices (Figure 4). The regression of the global SSTA on NINO3 reveals a large-scale pattern in the Pacific with negative poles around $40^{\circ} \mathrm{S}$ and $40^{\circ} \mathrm{N}$ and positive anomalies in most of the tropics and along the extra-tropical eastern boundaries of the basin, resembling a mix between the ENSO and PDO patterns [Zhang et al., 1997]. The explained variance of band-passed SSTA reaches up to $70 \%$ and $90 \%$ in the extra-tropical and tropical Pacific, respectively. There are weak positive anomalies in the Indian Ocean $(60 \%$ of band-passed 
variance). In the North Atlantic, the SSTA resembles the tripole structure that is generally attributed to NAO forcing [Cayan, 1992], combined with the tropical Atlantic dipole [Curtis and Hastenrath, 1995]. The explained band-passed variance of the northern (southern) lobe of the tripole reaches up to $40 \%(70 \%)$. The regression onto the bandpassed NAO index is highly similar, but with the inverse polarity (the pattern correlation is -0.93 ), except that there is no significant signal in the southern tropical Atlantic. The latter is consistent with the strong influence of ENSO on the tropical Atlantic SST. This analysis confirms that the Pacific and the Atlantic SSTA are significantly linked at periods of 10 to $20 \mathrm{yr}$.

[12] The regression of the northern hemisphere SLPA onto the band-passed indices shows highly similar atmospheric teleconnections (Figure 4). It indicates that the North Pacific and North Atlantic SLP varies in part in concert on the decadal timescales, with positive SLPA in the mid-latitudes (variance up to $60 \%$ ) and negative SLPA in the Icelandic low region (variance up to $60 \%$ for $\mathrm{NINO} 3$ and $70 \%$ for $\mathrm{NAO}$ ) associated with the positive and negative phase of the NAO and Nino3, respectively [Zhang et al., 1997].

\section{Discussion}

[13] In summary, by considering various observational climate indices of the last century we investigated the interbasin Pacific-North Atlantic teleconnection. We found a significant coherency and out-of-phase relation between ENSO and the NAO on interannual ( $\mathrm{T}=5-8 \mathrm{yr})$ and, more markedly, on decadal ( $\mathrm{T}=10-20 \mathrm{yr}$ ) timescales. Major patterns of climate variability such as the NPI and PDO also show significant coherence and consistent phase relations with NINO3 and the NAO, particularly at T $=10-20 \mathrm{yr}$, suggesting global teleconnections. At decadal frequencies, the coherency of the NPI and the PDO is stronger with the NAO than with NINO3, suggesting that the teleconnections may be driven by extratropical dynamics. Note that the phase relation between the NAO and the other indices was reversed near $\mathrm{T}=6$ to $8 \mathrm{yr}$ before 1925, suggesting a different NAO behavior (if not a statistical artefact). Regressions of SSTA and SLPA onto the band-passed filtered NAO and NINO3 confirm the strength of the northern hemisphere teleconnections, as it explains a large percentage of the band-passed variance near the extratropical centers of actions. The regression shows in particular a clear link between the decadal ENSO mode in the Pacific and the NAO-driven SSTA tripole in the North Atlantic. Regression of the SLPA onto the band-passed indices similarly shows co-varying patterns over the North Pacific and Atlantic that are indeed consistent with the link between the Pacific and the North Atlantic SSTA. The hemispheric SLP pattern resembles the Aleutian-Icelandic low seesaw (AII). Indeed the band-pass filtered time series of the AL and IL are significantly correlated with $\mathrm{r}=-0.80$. In contrast to the NAO, the AII has significant spectral peaks around $\mathrm{T}=15 \mathrm{yr}$ (Figure 1e). Moreover, the AII is largely coherent and out-of-phase with NINO3 at low frequency, the Aleutian low being intensified and the Icelandic low weakened during El Niño (Figure 2e), with a correlation between 10-20 yr band-passed data of -0.66 . Note that this correlation is larger than that between NINO3 and AL or IL separately $(r=-.53$ in both cases). This suggests that the AII is an important contributor to the decadal interbasin connections. If so, the North Pacific may be one of the originators of decadal teleconnections since the seesaw formation is triggered by eastward propagating Rossby wave trains from the North Pacific [Honda et al., 2001]. However, the mechanisms of low-frequency variability of the AII remain to be clarified. As the AII is strongest in the upper atmosphere, higher tropospheric levels should be considered, for example by reanalysis available for the entire period considered here [e.g., Compo et al., 2006].

[14] Finally, the relations investigated here could be used as metrics for the assessment of the performance of climate models. A preliminary comparison with the IPSL-CM4 [Marti et al., 2005] and ECHAM5/MPIOM [Jungclaus et al., 2006] models shows little coherency between the NAO and ENSO at the decadal timescale, both in historical and global warming conditions. Such discrepancy is disturbing since decadal variations in the global teleconnections should be well simulated if climate models are to be used for regional predictability studies.

[15] Acknowledgments. This study was supported by the European FP6 project DYNAMITE (contract 003903-GOCE) and ENSEMBLES (GOCE-CT-2003-505539) and (for CF) the Institut universitaire de France.

\section{References}

Allan, R. J. (2000), ENSO and climate variability in the past 150 years, in El Niño and the Southern Oscillation: Multiscale Variability and Global and Regional Impacts, edited by H. F. Diaz and V. Markgraf, pp. 3-56, Cambridge Univ. Press, Cambridge, U. K.

Bretherton, C. S., M. Widmann, V. Dymnikov, J. M. Wallace, and I. Blade (1999), The effective number of spatial degrees of freedom of a timevarying field, J. Clim., 12, 1990-2009.

Brönnimann, S. (2007), Impact of El Niño-Southern Oscillation on European climate, Rev. Geophys., 45, RG3003, doi:10.1029/2006RG000199.

Brönnimann, S., E. Xoplaki, C. Casty, A. Paulingand, and J. Luterbach (2007), ENSO influence on Europe during the last centuries, Clim. Dyn., 28, $181-197$.

Cayan, D. R. (1992), Latent and sensible heat flux anomalies over the northern oceans: The connection to monthly atmospheric circulation, J. Clim., 5, 354-369.

Cobb, K. M., C. D. Charles, and D. E. Hunter (2001), A central tropical Pacific coral demonstrates Pacific, Indian and Atlantic decadal climate connections, Geophys. Res. Lett., 28, 2209-2212.

Compo, G. P., J. S. Whitaker, and P. D. Sardeshmukh (2006), Feasibility of a 100 year reanalysis using only surface pressure data, Bull. Am. Meteorol. Soc., 87, 175-190.

Curtis, S., and S. Hastenrath (1995), Forcing of anomalous sea surface temperature evolution in the tropical Atlantic during Pacific warm events, J. Geophys. Res., 100, 15,835-15,847.

Deser, C., A. S. Phillips, and J. W. Hurrell (2004), Pacific interdecadal climate variability: Linkages between the Tropics and the North Pacific during boreal winter since 1900, J. Clim., 17, 3109-3124.

Fraedrich, K., and K. Müller (1992), Climate anomalies in Europe associated with ENSO extremes, Int. J. Climatol., 12, 25-31.

Frankignoul, C., and E. Kestenare (2005), Observed Atlantic SST anomaly impact on the NAO: An update, J. Clim., 18, 4089-4094.

Grinsted, A., J. C. Moore, and S. Jevrejeva (2004), Application of the cross wavelet transform and wavelet coherency to geophysical time series, Nonlinear Processes Geophys., 11, 561-566.

Honda, M., H. Nakamura, J. Ukita, I. Kousaka, and K. Takeuchi (2001), Interannual seesaw between the Aleutian and Icelandic lows. Part I: Seasonal dependence and life cycle, J. Clim., 14, 1029-1042.

Hurrell, J. W. (1996), Influence of variations in extratropical wintertime Teleconnections on Northern Hemisphere temperatures, Geophys. Res. Lett., 23, 665-668.

Jungclaus, J. H., et al. (2006), Ocean circulation and tropical variability in the coupled model ECHAM5/MPI-OM, J. Clim., 19, 3952-3972.

Kucharski, F., F. Molteni, and A. Bracco (2006), Decadal interactions between the western tropical Pacific and the North Atlantic Oscillation, Clim. Dyn., 26, 79-91. 
Mantua, N. J., S. R. Hare, Y. Zhang, J. M. Wallace, and R. C. Francis (1997), A Pacific interdecadal climate oscillation with impacts on salmon production, Bull. Am. Meteorol. Soc., 78, 1069-1079.

Marti, O., et al. (2005), The new IPSL climate system model: IPSL-CM4, Rep. 26, Inst. Pierre Simon Laplace, Paris.

Meehl, G. A., J. M. Arblaster, and W. G. Strand Jr. (1998), Global scale decadal climate variability, Geophys. Res. Lett., 25, 3983-3986.

Rayner, N. A., D. E. Parker, E. B. Horton, C. K. Folland, L. V. Alexander, D. P. Rowell, E. C. Kent, and A. Kaplan (2003), Global analyses of sea surface temperature, sea ice, and night marine air temperature since the late nineteenth century, J. Geophys. Res., 108(D14), 4407, doi:10.1029/ 2002JD002670

Schneider, N., and B. D. Cornuelle (2005), The forcing of the Pacific Decadal Oscillation, J. Clim., 18, 4355-4373.

Sutton, R. T., and D. L. R. Hodson (2003), Influence of the ocean on North Atlantic climate variability 1871-1999, J. Clim., 16, 3296-3313.
Torrence, C., and G. P. Compo (1998), A practical guide to wavelet analysis, Bull. Am. Meteorol. Soc., 9, 61-78.

Trenberth, K. E., and J. W. Hurrell (1994), Decadal atmosphere-ocean variations in the Pacifc, Clim. Dyn., 9, 303-319.

Trenberth, K. E., and D. A. Paolino (1980), The Northern Hemisphere sealevel pressure data set: Trends, errors and discontinuities, Mon. Weather Rev., 108, 855-872.

Zhang, Y., J. M. Wallace, and D. Battisti (1997), ENSO-like interdecadal variability: 1900-1993, J. Clim., 10, 1004-1020.

N. Chouaib and C. Frankignoul, LOCEAN, IPSL, Université Pierre et Marie Curie, 4, Place Jussieu, F-75252 Paris CEDEX 05, France.

W. Müller, Max Planck Institute for Meteorology, Bundesstrasse 53, D-20257 Hamburg, Germany. (wolfgang.mueller@zmaw.de) 